\title{
Determination of Material Constitutive Laws for Inconel 718 Superalloy Under Different Strain Rates and Working Temperatures
}

\author{
W. Grzesik, P. Niesłony, and P. Laskowski
}

\author{
(Submitted April 13, 2017; in revised form October 3, 2017; published online October 30, 2017)
}

\begin{abstract}
In this paper, a special procedure for the prediction of parameters of the Johnson-Cook constitutive material models is proposed based on the experimental data and specially developed MATLAB scripts which allow advanced modeling of complex 3D response surfaces. Experimental investigations concern two various strain rates of $10^{-3}$ and $10^{1} 1 / \mathrm{s}$ and the testing temperature ranging from the ambient up to $700{ }^{\circ} \mathrm{C}$. As a result, a set of mathematical equations which fit the experimental data is determined. The applicability of the experimentally derived constitutive models to the FEM modeling of real machining processes of Inconel 718 alloy is verified.
\end{abstract}

Keywords constitutive model, machining, modeling

\section{Introduction}

In modeling of the machining process and various machining operations using FEM technique, typically four material models including plastic, elastic-plastic, viscoplastic and elastic-viscoplastic material behavior are employed (Ref 1). In practice, more advanced constitutive material models which also consider strain hardening, thermal softening and microstructure changes as functions of three factors including strain, strain rate and temperature are applied. As a result, a number of different constitutive models which take into consideration these variable factors are used by FEM users (Ref 1-4). In this investigation, a classical Johnson-Cook model defined by Eq 1 is used.

$\sigma_{e q}=\left(A+B \varepsilon_{p}^{n}\right)\left(1+C \ln \left(\frac{\dot{\varepsilon}_{p}}{\dot{\varepsilon}_{p}^{0}}\right)\right)\left(1-\left(\frac{T-T_{o}}{T_{t}-T_{o}}\right)^{m}\right)$

where $\varepsilon_{p}$ is the equivalent strain; $\dot{\varepsilon}_{p}$ is the equivalent strain rate; $\dot{\varepsilon}_{p}^{0}$ is the reference strain rate; $T$ is temperature; $T_{0}$ is ambient temperature; $T_{t}$ is melting temperature; $A, B, C, n, m$ are material constants and exponents.

The Johnson-Cook (J-C) model is the most frequently used material constitutive model for characterizing the material behavior in the primary and secondary shear zones. It should be noted that the $\mathrm{J}-\mathrm{C}$ model given by $\mathrm{Eq} 1$ describes accurately plastic deformation below fracture initiation (equivalently to the separation of mesh nodes). On the other hand, the material fracture in the chip formation zone and an intensive thermal effect

W. Grzesik and P. Niesłony, Opole University of Technology, Opole, Poland; and P. Laskowski, Pratt \& Whitney, Rzeszow, Poland. Contact e-mail: p.nieslony@ po.opole.pl. should be considered in the material constitutive models used in the modeling of machining process. This aspect is particularly important in the machining of nickel-based alloys which retain high strength at a high temperature of above $800{ }^{\circ} \mathrm{C}$.

In order to consider the above-mentioned effects, some modifications of the $\mathrm{J}-\mathrm{C}$ model are proposed, as follows:

- thermal softening (Ref 3,4),

- thermal softening as a function of temperature (Ref 2, 5, $6)$,

- strain hardening for higher strain rates (Ref 7),

- microstructural changes (Ref 8,9).

Table 1 specifies the values of parameters in the $\mathrm{J}-\mathrm{C}$ model for Inconel 718 proposed in the literature from FEM-based modeling of machining processes and operations.

Based on the literature survey performed, the most adequate constitutive model for Inconel 718 seems to be that proposed by Uhlman et al. (Ref 10-12) (assigned by symbol II in Table 1). This model implemented into DEFORM software gives a good agreement between measured and FEM-predicted values of component cutting forces. In addition, it was revealed that in the J-C model the thermal softening effect does not depend on the strain rate. On the other hand, the value of $\mathrm{C}$ parameter depends on both temperature and strain rate. For this reason, a method proposed by Warnecke and Oh (Ref 13) is developed. For the temperature ranging between 500 and 800 ${ }^{\circ} \mathrm{C}$, the maximum value of $\mathrm{C}$ parameter changes from 0.017 to 0.0271. Based on mathematical modeling, the authors observed that such changes of $\mathrm{C}$ parameter do not influence the strain hardening module in $\mathrm{Eq} \mathrm{1.} \mathrm{In} \mathrm{fact,} \mathrm{the} \mathrm{equivalent} \mathrm{flow} \mathrm{stress}$ $\sigma_{e q}$ changes only in the range of several percent.

Typical approaches for numerical modeling of metal cutting processes are Lagrangian and Eulerian techniques, as well as a combination of both called an arbitrary Lagrangian-Eulerian formulation (ALE) (Ref 1). For Lagrangian formulation, the discretized mesh is attached to the workpiece and the material model is elastic-plastic, only plastic or viscoplastic, whereas for Eulerian finite element models, the workpiece material is assumed to flow through a meshed control volume creating the 
Table 1 Typical values of parameters of $\mathrm{J}-\mathrm{C}$ model for Inconel 718 alloy appearing in the literature

\begin{tabular}{lrrllll}
\hline Code & $\boldsymbol{A}$, MPa & $\boldsymbol{B}$, MPa & $\boldsymbol{n}$ & $\boldsymbol{C}$ & $\boldsymbol{m}$ & Literature item \\
\hline I & 1241 & 622 & 0.652 & 0.0134 & 1.30 & 9,10 \\
II & 450 & 1700 & 0.65 & 0.017 & 1.30 & 6,7 \\
III & 1485 & 1139 & 0.777 & 0.015 & 1.69 & 11,12 \\
IV & 1350 & 0.6522 & 0.0134 & 1.00 & 13 \\
\hline
\end{tabular}

cutting zone and the strain has to be computed from the strain rates by integrating along streamlines. The ALE formulation is needed to relate the stationary (Eulerian) frame to the moving (Lagrangian) frame. In this study, the finite element model implemented into AdvantEdge package is based on the Lagrangian techniques and an explicit dynamic, thermomechanically coupled modeling software with adaptive remeshing (Ref 14). This means that the initial mesh becomes distorted after a certain length of cut and is remeshed in this vicinity to form a regular mesh again. In simulations with AdvantEdge, there is no separation criterion defined, and then, chip formation is assumed to be resulting from plastic flow. Therefore, the chip is formed by continuously remeshing the workpiece.

\section{Derivation of J-C Constitutive Model for Inconel 718}

\subsection{Determination of Material Constitutive Models}

This study is focused on establishing a technologically acceptable material constitutive model for the purpose of FEM simulations of both turning and milling operations performed on parts of jet engines made of an Inconel 718 nickel-based alloy. The main tasks include detailed analysis of a number of material constitutive models applicable for FEM simulations (Table 1), their verification based on the literature data in special applications to difficult-to-machine aerospace materials and the final choice of the sufficient material constitutive models in order to simulate appropriately machining processes and technological operations.

The first step is concentrated on the selection of material parameters in the material constitutive models accepted. It was done in relation to the mechanical and thermal influences on the material behavior during metal cutting. All material data concerning nickel-based alloys machined, needed for FEM simulations, were provided by the aerospace plants in Poland. Based on these data, a special database is created. All these modeling activities are performed with the assistance of a MATLAB program.

\subsection{Experimental Methodology}

The general concept of this experimental study along with material deformation and thermal softening conditions is illustrated in the form of a flow chart in Fig. 1. As shown in Fig. 1, the determination of parameters corresponding to the three terms of the $\mathrm{J}-\mathrm{C}$ model needs the application of different measurement techniques and relevant apparatus, i.e., a tensile testing machine, a dilatometer and the split Hopkinson's pressure bar (SHPB) apparatus.

In this study, the following devices and apparatus are used:
1. The testing machine model INSTRON 5982 equipped with a heating chamber for static tensile tests performed under the test temperature of $20-700{ }^{\circ} \mathrm{C}$.

2. The dilatometer model BÄHR $850 \mathrm{D} / \mathrm{L}$ in order to establish the material behavior at a higher strain rate of $\dot{\varepsilon}_{p}=12.51 / \mathrm{s}$ and a very high temperature of $900{ }^{\circ} \mathrm{C}$.

3. Split Hopkinson's pressure bar device designed by Polish Technical Military Academy in Warsaw in order to determine the influence of the strain rate on the material flow stress.

At the first stage of this experimental study, the material data from static tensile tests which are carried out at the temperature ranging between 20 and $700{ }^{\circ} \mathrm{C}$ provided by industrial partner are analyzed and converted to MATLAB program by means of appropriate mathematical transformations. For this purpose, a special script is elaborated and the possible mathematical solutions are made automatically.

When this script is activated, the files of "mat" type are generated and selected in terms of different test temperatures. They concern the data obtained for a static tensile test performed with low strain rates limited by linear movement of the testing machine, i.e., $\dot{\varepsilon}_{p}^{0}=2.604 \cdot 10^{-3} 1 / \mathrm{s}$. The function $\sigma=f(\varepsilon, T)$ is related to both elastic and plastic strains, but for FEM modeling only constitutive material models describing plastic material behavior are used. Consequently, the separation of elastic and plastic strains using the experimentally determined values of Young modulus $\mathrm{E}$ for all ranges of the temperature is performed.

In order to determine the values of variable parameters in the $\mathrm{J}-\mathrm{C}$ material model, the matrix of points with constant variation step is defined. This allows the approximation of data to the selected constitutive model using subprogram Sftools available in MATLAB program. An example of point arrangements for the approximation in the plastic region is shown in Fig. 2(b).

Figure 2(b) shows the values of the equivalent flow stress obtained for different plastic deformation (0.01-0.08) and different test temperatures $\left(20-700{ }^{\circ} \mathrm{C}\right)$. They were experimentally obtained using the testing tensile machine model INSTRON 5982 equipped with a special heating chamber (see section 2.2) (point \#1). The relevant parameters of $\mathrm{J}-\mathrm{C}$ constitutive model (case M1) are specified in Table 2. Also two modified versions (cases M2 and M3) are proposed for the temperature range limited to $400-700{ }^{\circ} \mathrm{C}$.

\subsection{Mathematical Function Fitting}

The mathematical (response) function of the J-C material model expressed by Eq 1 is determined using Sftool module available in MATLAB program. First, using Customer Equation function, the $\mathrm{J}-\mathrm{C}$ equation is inserted after some modifications. It is assumed that in the first step the model parameters 


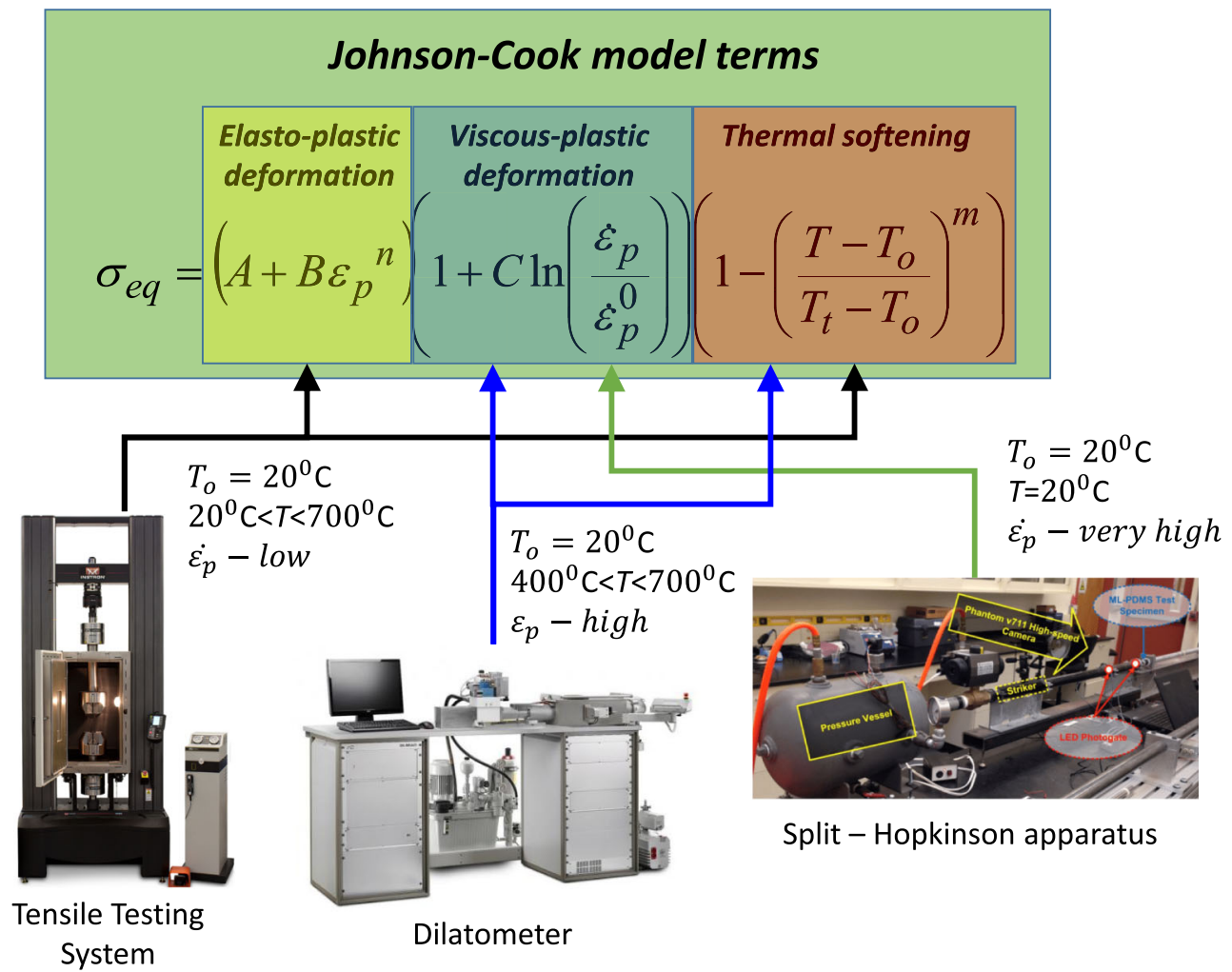

Fig. 1 Flow chart of material testing under different deformation and thermal conditions (symbols: $T_{0}$, reference temperature; $T$, test temperature; $\varepsilon_{p}$-plastic strain; $\dot{\varepsilon}_{p}$, strain rate)

Table 2 Experimentally obtained parameters of J-C model for Inconel 718 alloy

\begin{tabular}{lcccrr}
\hline Code & $\boldsymbol{A}, \mathbf{M P a}$ & $\boldsymbol{B}, \mathbf{M P a}$ & $\boldsymbol{n}$ & $\boldsymbol{C}$ \\
\hline M1 & 1012 & 393 & 0.125 & 0.0271 & \\
M2 & 1012 & 511 & 0.396 & 0.0271 & 2.42 \\
M3 & 1012 & 513 & 0.422 & 0.0271 & 4.33 \\
\hline
\end{tabular}

are determined for the stress state corresponding to low strain rates.

Correspondingly, the term of Eq 1 with strain rate $\dot{\varepsilon}_{p}$ is equal to 1 . It is established that for an Inconel 718 the melting temperature changes in the range of $T_{m}=1250-1294{ }^{\circ} \mathrm{C}$. As a result, the average melting temperature is assumed to be equal to $T_{m}=1277^{\circ} \mathrm{C}$.

The graphical window of Sftool function showing the generated response function fitted to the experimentally obtained points is presented in Fig. 3 .

The mathematical function of the $\mathrm{J}-\mathrm{C}$ constitutive material model generated for lower strain rates $\left(\dot{\varepsilon}_{p}^{0}=2.604 \cdot 10^{-3} 1 / \mathrm{s}\right)$ and fitted with the R-square of 0.6283 is as follows

$f\left(T, \varepsilon_{p}\right)=\left(1012+393 * \varepsilon_{p} \wedge 0.125\right) *(1-((T-20)$

$$
/ 1255) \wedge 2.42)
$$

Because the machined material in the cutting zone is subjected to severe plastic deformation under high strain rates, the appropriate model parameters in the module expressing the influence of strain rate on the plastic deformation, especially at high temperatures, are necessary.

The material tests performed using the dilatometer allow the flow stress values $\sigma=f\left(\varepsilon_{p}, T\right)$ for strain rate of $\dot{\varepsilon}_{p}=12.51 / \mathrm{s}$ to be determined. It can be noted that in this case strain rates are three levels higher than previously, i.e., $\dot{\varepsilon}_{p}^{0}=2.604 \cdot 10^{-3} 1 / \mathrm{s}$.

Finally, the relationships expressing the flow stresses as the function of plastic deformation for the higher strain rate are obtained. In addition, similarly as for lower strain rates $\dot{\varepsilon}_{p}^{0}$, points for the matrix approximating the data set are identified using subprogram Sftools available in MATLAB program.

The function of the $\mathrm{J}-\mathrm{C}$ constitutive material model applicable for low and high strain rates is defined by Eq 3 as follows (case M1 in Table 1)

$$
\begin{aligned}
f\left(T, \varepsilon_{p}, \dot{\varepsilon}_{p}\right)= & \left(1012+393 * \varepsilon_{p} \wedge 0.125\right) \\
& *\left(1+0.0271 * \ln \left(\dot{\varepsilon}_{p} / \dot{\varepsilon}_{p}^{0}\right)\right) \\
& *(1-((T-20) / 1255) \wedge 2.42)
\end{aligned}
$$

It is revealed based on the machining experiments that the values of the cutting temperature recorded during finish turning 

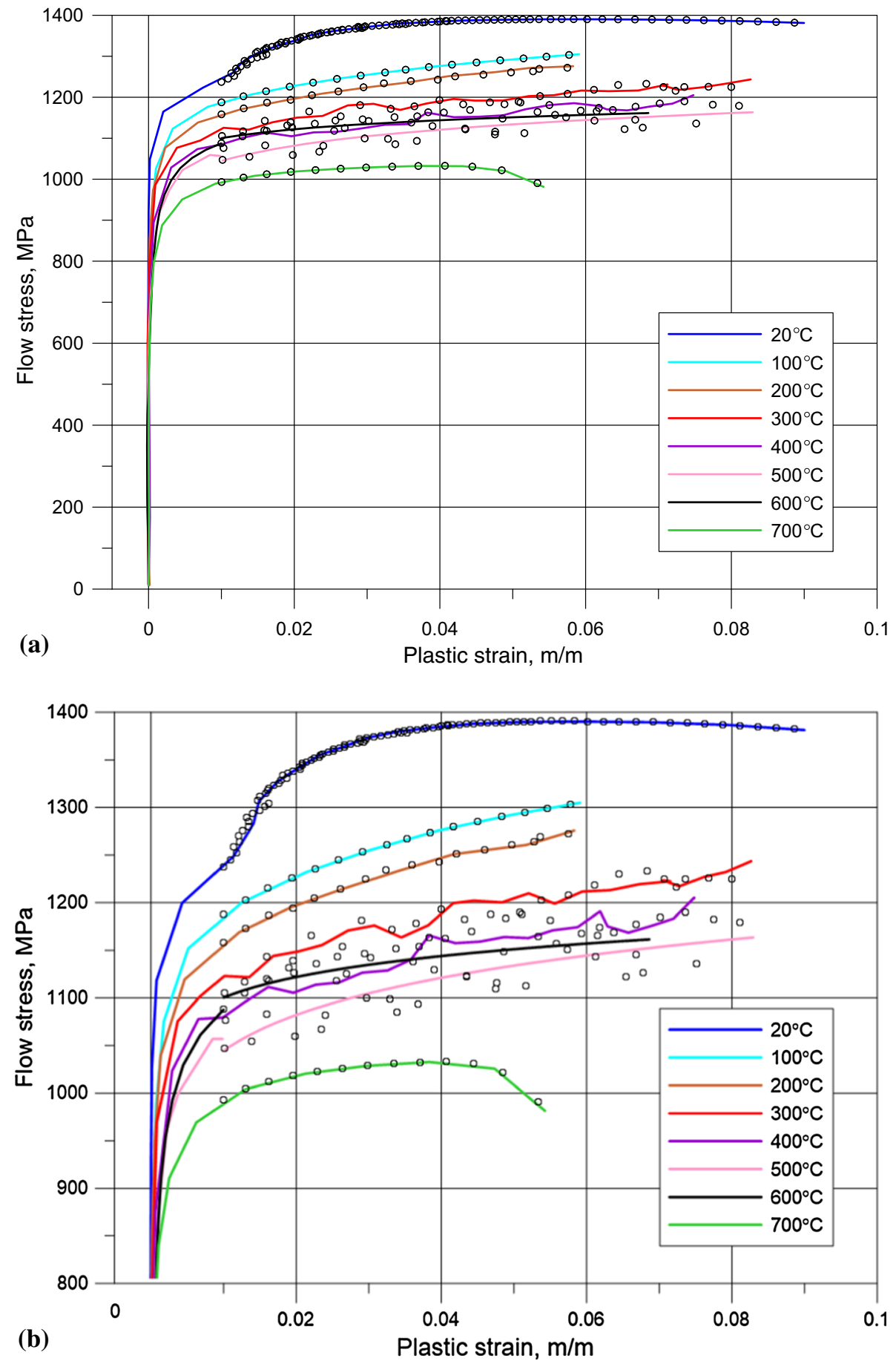

Fig. 2 Graph $\sigma=f\left(\varepsilon_{p}, T\right)$ showing two ranges of stresses above yield stress with marked experimental points: (a) full range and (b) flow stress changing from 800 to $1400 \mathrm{MPa}$

operations of an Inconel 718 alloy with TiAlN-coated carbide tools varied between 500 and $700{ }^{\circ} \mathrm{C}$ depending on cutting parameters used. Consequently, the appropriate constitutive model was limited to the temperature range of $T=400-700{ }^{\circ} \mathrm{C}$ in order to increase the prediction accuracy. As a result, the mathematical function of the $\mathrm{J}-\mathrm{C}$ constitutive material model suitable for low and high strain rates for $T=400-700{ }^{\circ} \mathrm{C}$ (case $\mathrm{M} 2$ in Table 1) is defined by Eq 4 as follows

$$
\begin{aligned}
f\left(T, \varepsilon_{p}, \dot{\varepsilon}_{p}\right)= & \left(1012+511 * \varepsilon_{p} \wedge 0.396\right) \\
& *\left(1+0.0271 * \ln \left(\dot{\varepsilon}_{p} / \dot{\varepsilon}_{p}^{0}\right)\right) \\
& *(1-((T-20) / 1255) \wedge 4.33)
\end{aligned}
$$

For the temperature range of $T=400-700{ }^{\circ} \mathrm{C}$ and the reference temperature $T_{0}=400{ }^{\circ} \mathrm{C}$, the function of the $\mathrm{J}-\mathrm{C}$ constitutive material model suitable for low and high strain rates is defined by Eq 5 as follows (case M3 in Table 1) 


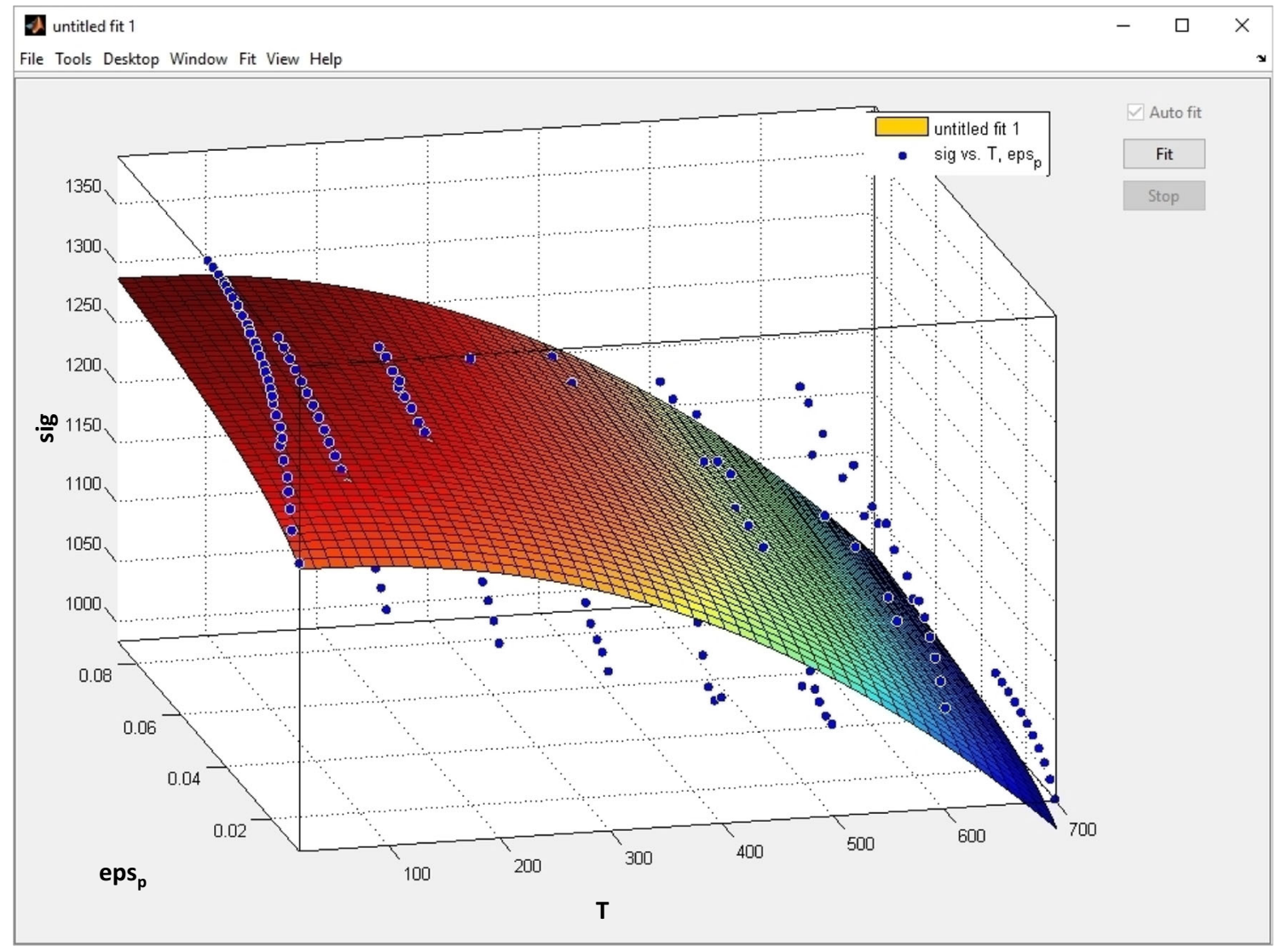

Fig. 3 Window of Sftool module after approximation of a set of experimental points using mathematical function given by Eq 1

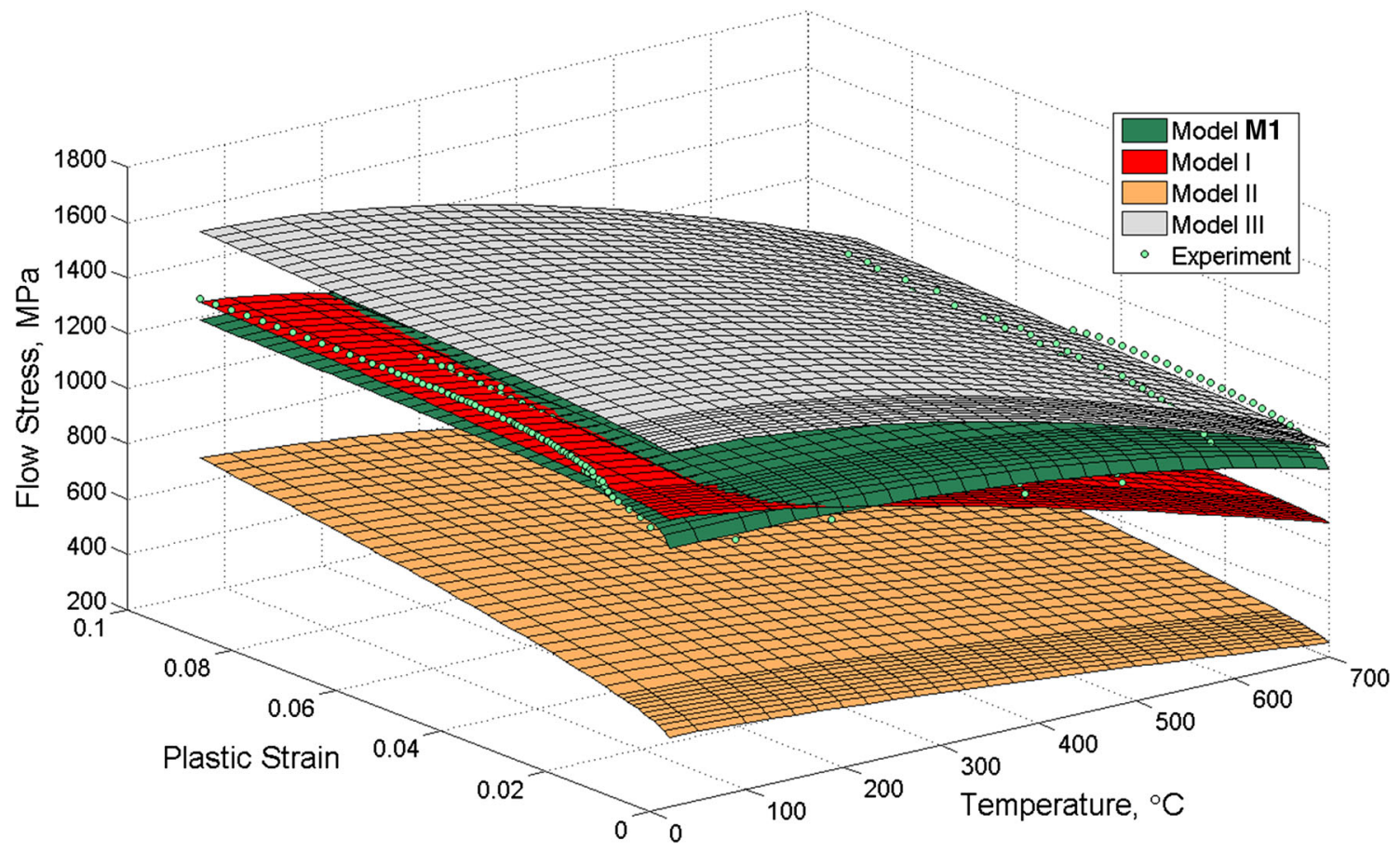

Fig. 4 Response surfaces for the literature data and experimentally derived J-C models defined in Table 1 generated for temperature range of $T=20-700{ }^{\circ} \mathrm{C}$ 




Fig. 5 Experimentally derived J-C models for $T=400-700{ }^{\circ} \mathrm{C}$ and for different values of reference temperature $T_{0}$

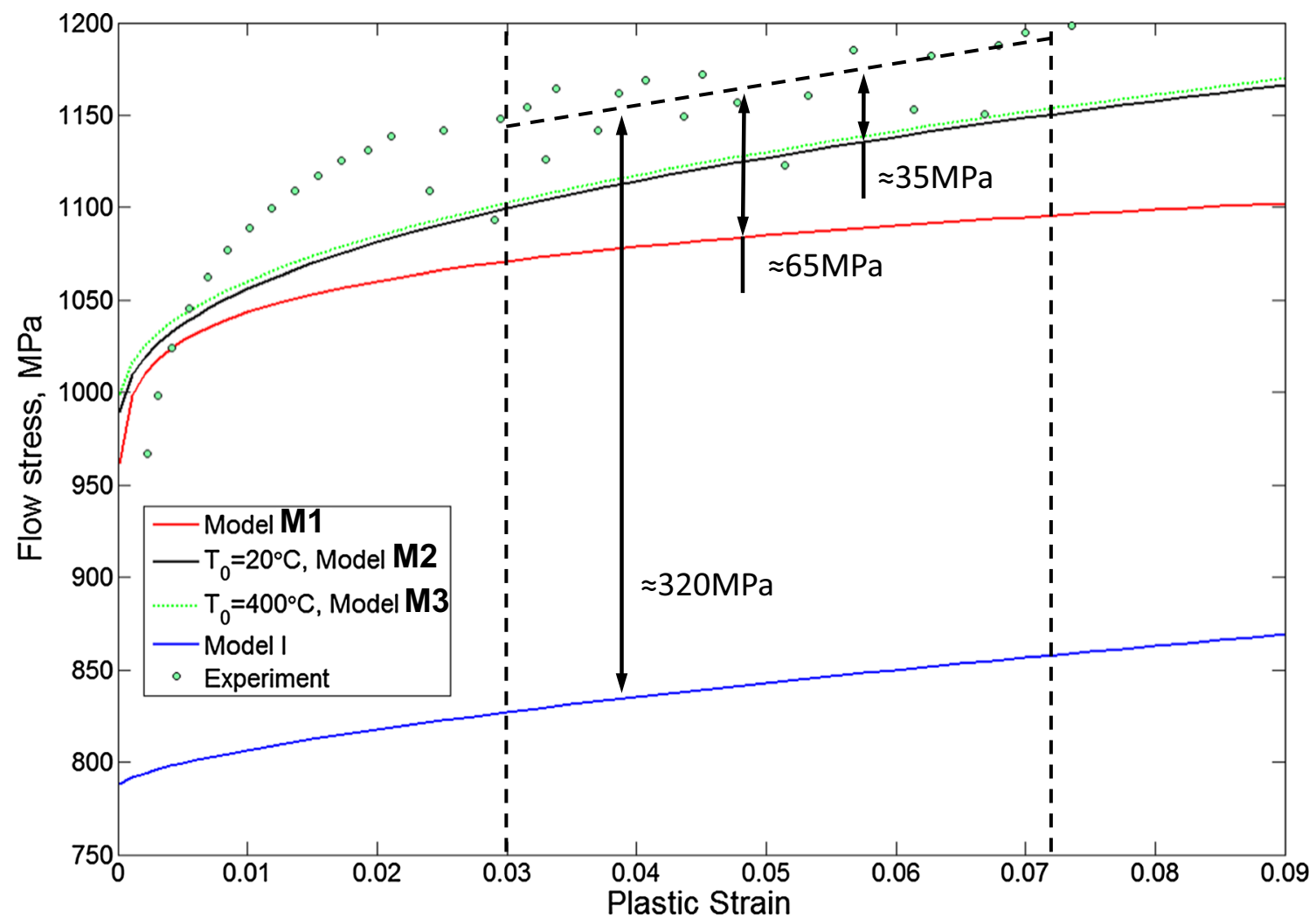

Fig. 6 Comparative visualization of the derived J-C models M1, M2 and M3 vs. experimental points for a low strain rate and temperature $T=600{ }^{\circ} \mathrm{C}$ 


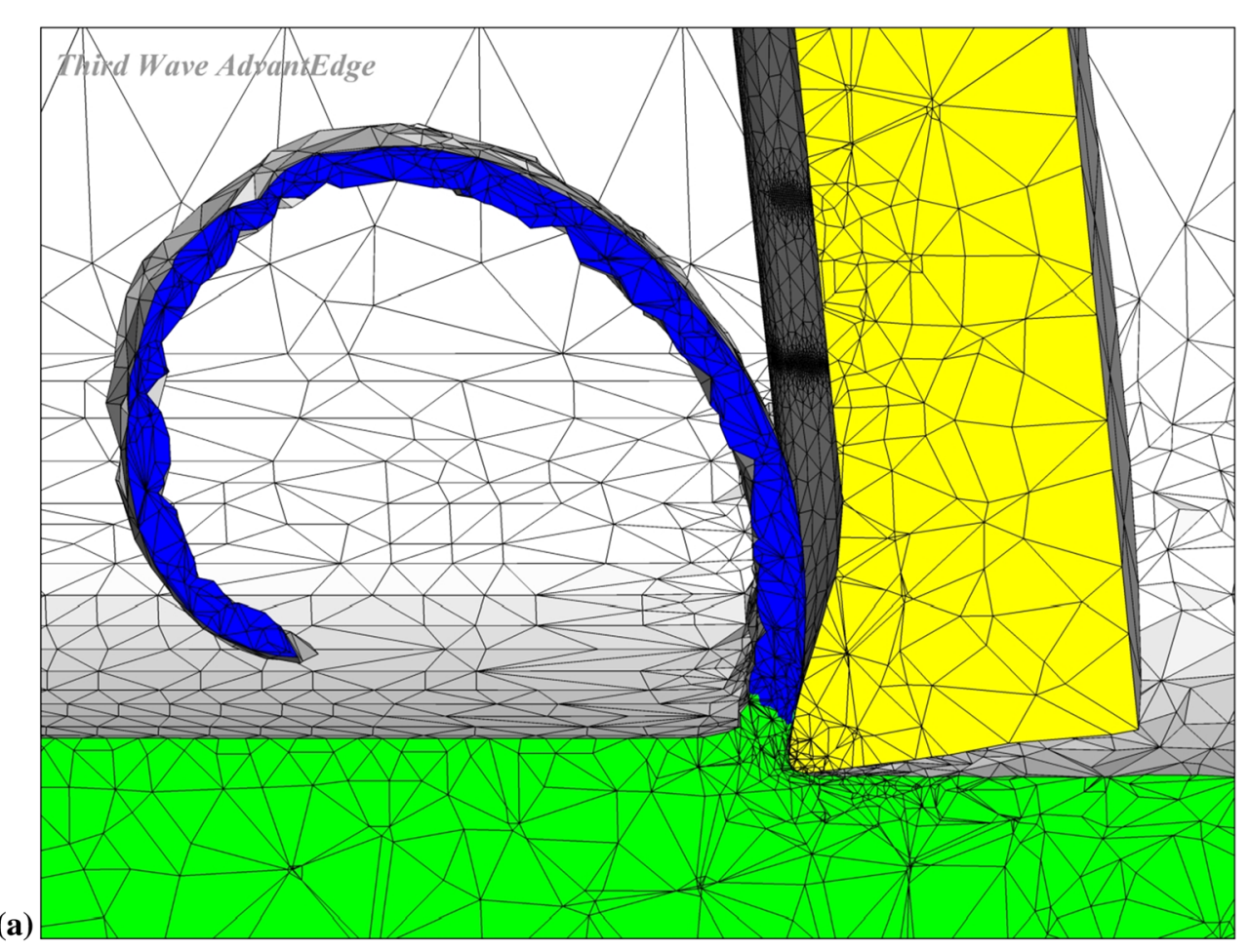

(a)

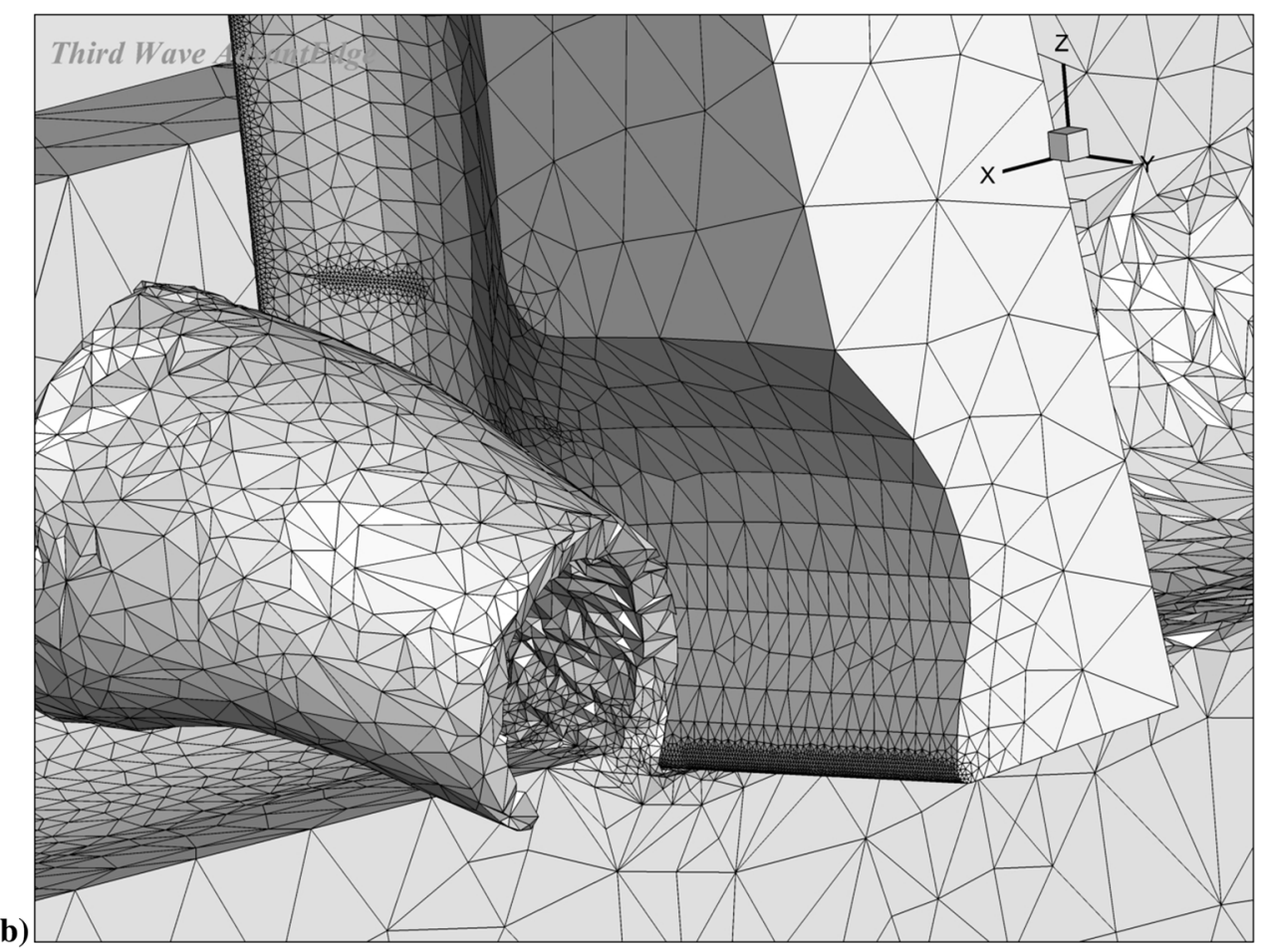

Fig. 7 FEM mesh nets of the cutting zone for 2D (a) and 3D (b) arrangements

$$
\begin{aligned}
f\left(T, \varepsilon_{p}, \dot{\varepsilon}_{p}\right)= & \left(1012+513 * \varepsilon_{p} \wedge 0.422\right) \\
& *\left(1+0.0271 * \ln \left(\dot{\varepsilon}_{p} / \dot{\varepsilon}_{p}^{0}\right)\right) \\
& *(1-((T-400) / 877) \wedge 2.54)
\end{aligned}
$$

Table 2 specifies the values of parameters in the J-C model for Inconel 718 determined for the two temperature ranges of $T=20-700{ }^{\circ} \mathrm{C}(\mathrm{M} 1)$ and $T=400-700{ }^{\circ} \mathrm{C}$, where in the models
M2 and M3 the reference temperature is fixed at 20 and $400{ }^{\circ} \mathrm{C}$, respectively.

\subsection{Comparison of Mathematical Functions of J-C Model}

The comparison of the experimentally derived model M1 with the three literature models I, II and III for the strain rate $\dot{\varepsilon}_{p}^{0}=2.604 \cdot 10^{-3} 1 / \mathrm{s}$ is shown in Fig. 4 . 


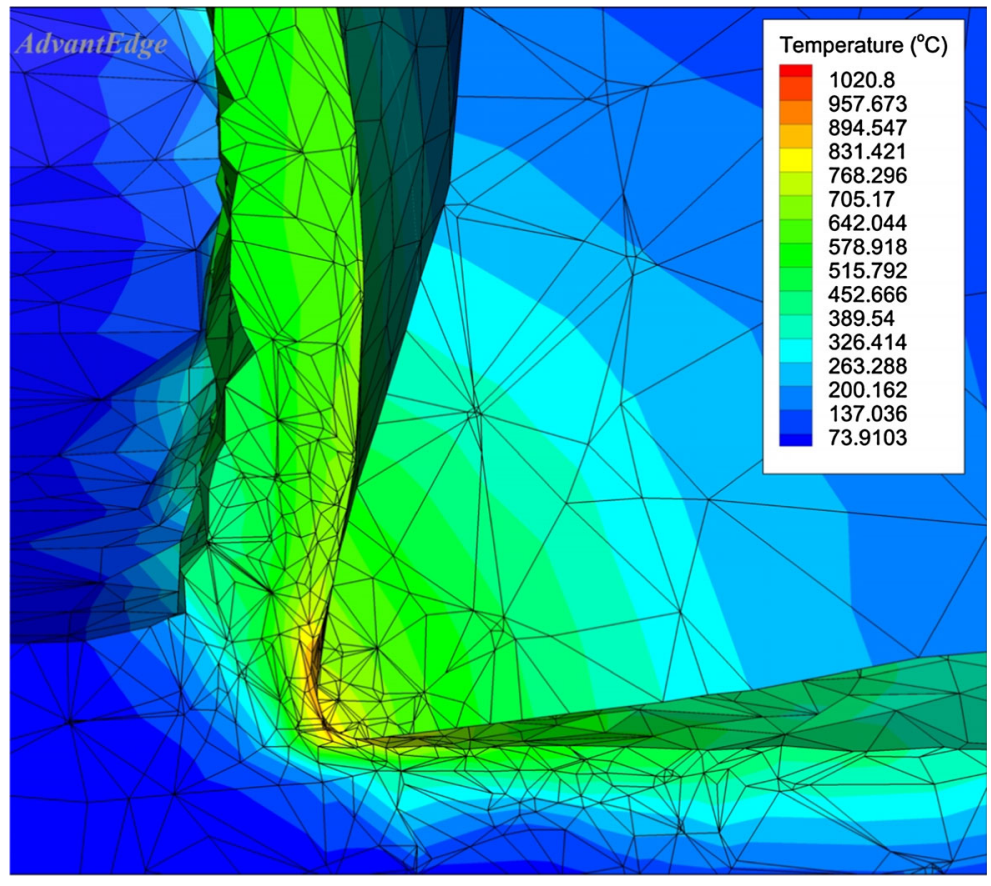

(a)

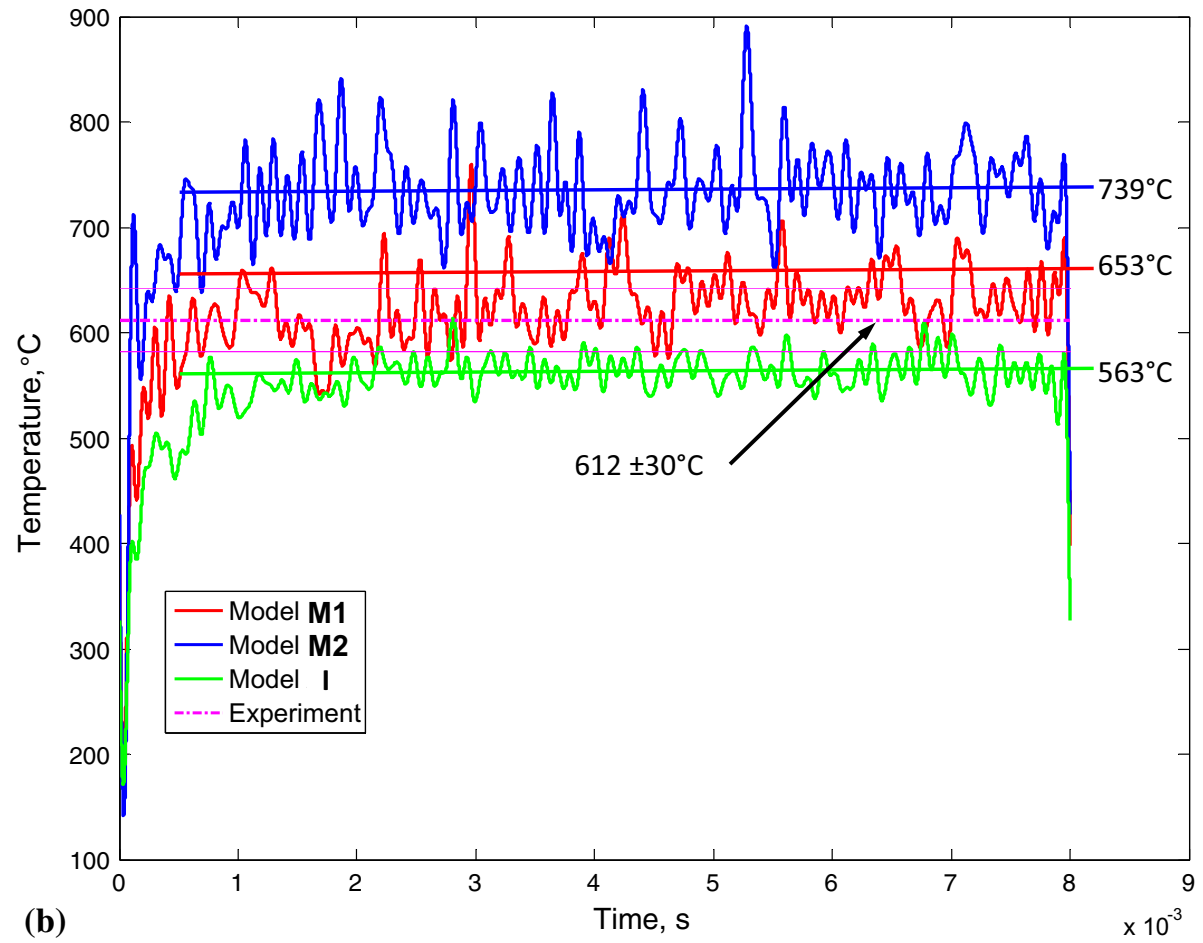

Fig. 8 Simulated distribution of temperature in the cutting zone (a) and comparison of FEM-predicted temperatures using different experimentally derived (M1 and M2) and the literature (I) J-C models (b)

As shown in Fig. 4, the frequently quoted model II (Ref 10, 11) gives the worse fitting to the experimental data. On the other hand, a good agreement for the temperatures above $600{ }^{\circ} \mathrm{C}$ was achieved by both the literature III and experimentally derived M1 models. It should also be noted in Fig. 4 that the model I approximates better experimental points in the lower range of temperatures of $T=20-300{ }^{\circ} \mathrm{C}$. Based on these important findings, the actual constitutive model M2 was limited to the experimental points obtained for higher testing temperatures.

In addition, this comparison covers the modeling effects for the reference temperatures of $T_{0}=20$ and $400{ }^{\circ} \mathrm{C}$ as presented in Fig. 5. The R-square values for these two modeling cases are equal to 0.7554 and 0.7639 for $T_{0}=20^{\circ} \mathrm{C}$ and $T_{0}=400{ }^{\circ} \mathrm{C}$, respectively (see also Fig. 6). It should be noticed that the FEM simulations using the J-C model type M2 are narrowed down to 


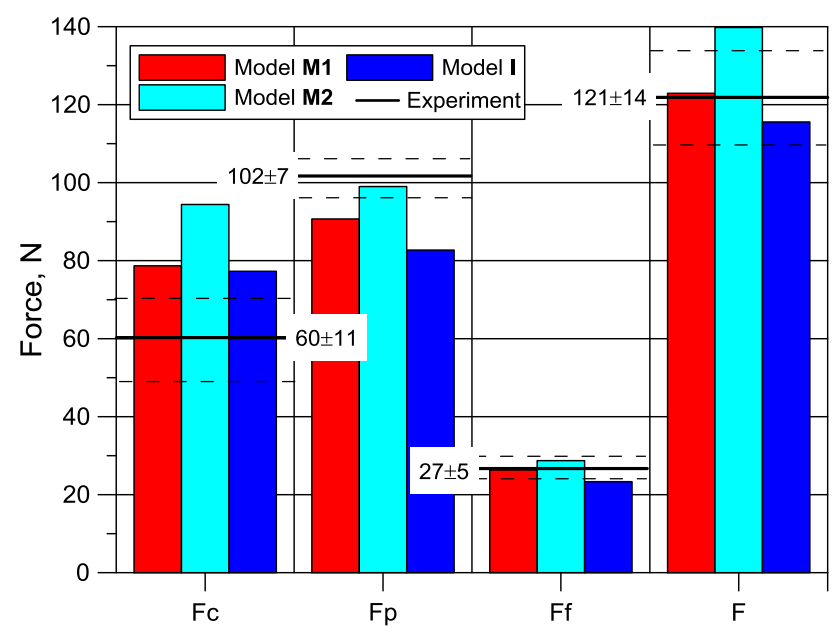

Fig. 9 Comparison of FEM-predicted componential forces with experimental data using different $\mathrm{J}-\mathrm{C}$ models. Experimental standard deviation fixed at $95 \%$

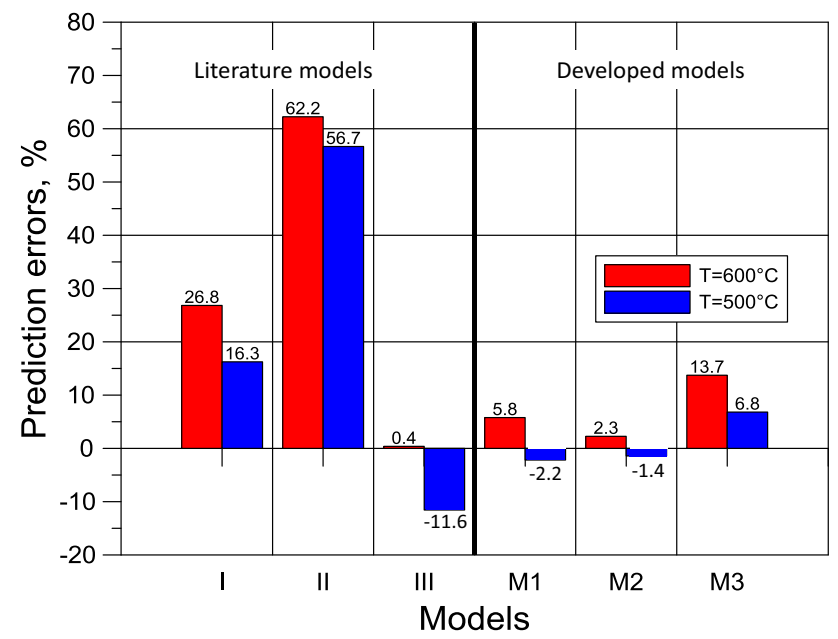

Fig. 10 Prediction errors resulting from application of the literature models (I, II and III) and derived models (M1, M2 and M3) for temperatures of $\mathrm{T}=500$ and $600{ }^{\circ} \mathrm{C}$ and plastic strain $\varepsilon_{p}$ in the range of 0.03-0.07

the temperatures higher than $T>400{ }^{\circ} \mathrm{C}$. It results from the special mathematical description of the thermal softening module in the $\mathrm{J}-\mathrm{C}$ model given by $\mathrm{Eq} 1$ for which for temperature $T<T_{0}$ and the exponent $m$ being a rational number its computation is not possible.

Taking into account small differences in the predicted values of the flow stress in this study, the FEM simulations were carried out using the $\mathrm{J}-\mathrm{C}$ model at the ambient $T_{0}=20{ }^{\circ} \mathrm{C}$ (case M2 in Table 1).

Figure 6 shows a comparison between predicted and experimental values of the flow stress determined for the temperature of $600{ }^{\circ} \mathrm{C}$ (this plot is the cross section of four spatial surfaces in the stress-strain plane shown in Fig. 5). The selected temperature is the average cutting temperature measured in finish turning of an Inconel 718 alloy using the natural thermocouple technique. The accuracy the FEM predictions is discussed in detail in section 4 .
Figure 6 reveals that the best fitting of the experimental points to the mathematical model is observed for the models M2 and M3 for which the average variation is about $35 \mathrm{MPa}$ (equivalently about $3 \%$ when the flow stress is about $1150 \mathrm{MPa}$ ). Appropriately, for the M1 model the difference increases to about $65 \mathrm{MPa}$. In contrast, the J-C model I predicts the measured flow stress with a distinctly higher variation of about $320 \mathrm{MPa}$ (equivalent to about $35 \%$ ).

\section{Validation of New Mathematical Functions of J-C Model by FEM Simulation}

The J-C constitutive models selected are validated for a finish turning operation using the cutting speed of $v_{c}=90 \mathrm{~m} /$ $\mathrm{min}$, the feed rate of $f=0.05 \mathrm{~mm} / \mathrm{rev}$ and the depth of cut of $a_{p}=0.125 \mathrm{~mm}$.

The cutting tool inserts of CNMG 120412-UP type made of PVD-TiAlN-coated sintered carbide (KC5010 grade by Kennametal) were used. In these FEM simulations, the experimentally determined values of the thermal conductivity and the specific heat as functions of the temperature were applied based on the data presented in Ref 2.

The FEM simulations of turning operations of Inconel 718 alloy are carried out using commercial AdvantEdge software. It is assumed based on the previous simulations using the same tool material-workpiece material pair (Ref 15) that the maximum tool element size is equal to $0.5 \mathrm{~mm}$, the minimum tool element size is equal to $0.005 \mathrm{~mm}$ and the minimum edge length is equal to $0.001 \mathrm{~mm}$. For this software, the number of segments per edge unit is set to 1.0 from the range $0.2-5$. It should be noted that the increase in this parameter results in increasing the number of nodes and, as a result, the edges of finite elements.

Figure 7 visualizes FEM mesh nets of the cutting zone for both 2D (Fig. 7a) and 3D (Fig. 7b) arrangements. In this case, the first-order tetra mesh-tetrahedral elements with the maximum tool element size of $0.5 \mathrm{~mm}$; the minimum tool element size of $0.005 \mathrm{~mm}(50 \mu \mathrm{m})$; and the minimum edge length of $0.001 \mathrm{~mm}(10 \mu \mathrm{m})$ were adopted (Ref 15). It should be noted in Fig. 7 that the meshing smoothing or coarsening results predominantly from more accurate representation of the cutting edge (its radius was equal to about $40 \mu \mathrm{m}$ ).

Figure 8 presents FEM-predicted distribution of temperature in the cutting zone (Fig. 8a) and the records of temperature evolution obtained for differently parameterized J-C models with measured values represented by their average values (the temperature variation is $612 \pm 30^{\circ} \mathrm{C}$ ) (Fig. 8b). It can be noted that in the FEM simulations the value of friction coefficient was assumed to be equal to $\mu=0.5$, similar as in Ref 16 . Figure 8(b) shows that the best fitting to the measured temperatures is provided by the M1 model type, J-C constitutive model with the lowest values of $B$ parameter and $n$ exponent in the first elastic-plastic term. A similar effect, but with visibly underestimated temperature values is obtained using the literature model I, but with quite a different set of the model parameters. In contrast, both M2 and I models result in a distinct overestimation of the simulated temperatures in comparison with the measurements even by $125^{\circ} \mathrm{C}$.

Figure 9 presents the simulated values of the three components of the resultant cutting force using two experimentally 
derived M1 and M2 models and the literature model I similarly as in the thermal outputs. Figure 9 shows that the best prediction accuracy was obtained for both the passive $F_{p}$ and feed $F_{f}$ forces using M2 type model. For these forces, the average experimental and predicted values differ only by $1-2 \%$. A worse result obtained for the cutting force $F_{c}$ is probably due to an excessive strain hardening effect obviously occurring during machining of difficult-to-machine alloys. As reported previously, the accurate simulation of the $F_{c}$ forces is performed using the II type J-C constitutive model with evidently pronounced strain effect (the highest value of $\mathrm{B}$ parameter in the first elastic-plastic term). On the other hand, the measured and predicted values of the resultant cutting force agree well $(\mathrm{F}=121 \pm 13 \mathrm{~N}$ versus $123 \mathrm{~N}$ for the model M1, and $140 \mathrm{~N}$ and $115 \mathrm{~N}$ for models M2 and I, respectively).

The comparison of prediction errors resulting from applications of different literature and experimentally derived material models is shown in Fig. 10. It is evident in Fig. 10 that all three new material constitutive models M1, M2 and M3 outperform distinctly all the literature models depending on the value of the working temperature. In general, higher prediction accuracy is achieved when the working/testing temperature is equal to $500{ }^{\circ} \mathrm{C}$. In particular, the best fitting of the FEM predictions with the relevant errors lower than $2 \%$ to the experimental data is obtained for the two models I and II (the right part of Fig. 10).

\section{Conclusions}

1. A visible increase in simulation accuracy regarding the cutting temperature and componential cutting forces was achieved by using the experimentally derived J-C models.

2. Special mathematical procedure was elaborated for spatial modeling of the $\mathrm{J}-\mathrm{C}$ constitutive models characterized by different sets of $\mathrm{A}, \mathrm{B}$ and $\mathrm{C}$ parameters, and $m$ and $n$ exponents.

3. In this study, the experimentally derived J-C constitutive model M2 allows the cutting temperature and the feed and passive forces to be predicted with high accuracy. In all these cases, the prediction error is not higher than 1$2 \%$.

4. In this study, FEM simulations were carried out using the AdvantEdge package which requires the basic $\mathrm{J}-\mathrm{C}$ model given by Eq 1 as the input. The proposed M2 model can be described by other mathematical models without restrictions for the reference temperature in the third softening term, and as a result, the FEM simulations can be carried out using an open FEM package like Abaqus.

\section{Acknowledgments}

A financial support of The National Centre for Research and Development Project No INNOLOT///9/NCBR/2013 “Advanced methods for manufacturing of aero engine case module components"'-CASELOT-is gratefully acknowledged. A financial support of The National Centre for Research and Development Project No INNOLOT/I/7/NCBR/2013 “Turbine for Turboshaft Engine Demonstrator' - TED—is gratefully acknowledged.

\section{Open Access}

This article is distributed under the terms of the Creative Commons Attribution 4.0 International License (http://crea tivecommons.org/licenses/by/4.0/), which permits unrestricted use, distribution, and reproduction in any medium, provided you give appropriate credit to the original author(s) and the source, provide a link to the Creative Commons license, and indicate if changes were made.

\section{References}

1. W. Grzesik, Advanced Machining Processes of Metallic Materials, Elsevier, Amsterdam, 2017

2. P. Niesłony, Modelling of Heat Transfer and Temperature Distribution in the Cutting Zone for Cutting Tools Coated with Protective Hard Layers, Dsc. Monograph, Opole University of Technology, Opole, 2008 (in Polish)

3. M. Calamaz, D. Coupard, and F. Girot, A New Material Model for 2D Numerical Simulation of Serrated Chip Formation When Machining Titanium Alloy Ti-6Al-4 V, Int. J. Mach. Tools Manuf., 2008, 48, p 275-288

4. F. Ducobu, E. Rivière-Lorphèvre, and E. Filippi, Influence of the Material Behavior Law and Damage Value on the Results of an Orthogonal Cutting Finite Element Model of Ti6Al4V, Proc. CIRP, 2013,8 , p 378-383

5. T. Ozel, I. Llanos, J. Soriano, and P.-J. Arrazola, 3D Finite Element Modelling of Chip Formation Process for Machining Inconel 718: Comparison of the Software Predictions, Mach. Sci. Technol., 2011, 15(1), p 21-46

6. A. Iturbe, E. Giraud, E. Hormaetxe, A. Garay, G. Germain, K. Ostolaza, and P.J. Arrazola, Mechanical Characterization and Modelling of Inconel 718 Material Behavior for Machining Process Assessment, Mater. Sci. Eng. A, 2017, 682, p 441-453

7. X. Wang, Ch Huang, B. Zou, H. Liu, H. Zhu, and J. Wang, Dynamic Behavior and a Modified Johnson-Cook Constitutive Model of Inconel 718 at High Strain Rate and Elevated Temperature, Mater. Sci. Eng. A, 2013, 580, p 385-390

8. A.D. Prete, L. Filice, and D. Umbrello, Numerical Simulation of Machining Nickel-Based Alloys, 14th CIRP Conference on Modeling of Machining Operations (CIRP CMMO), Proceedings of CIRP, 2013, 8, p 540-545

9. F. Jafarian, M. ImazCiaran, D. Umbrello, P.J. Arrazola, L. Filice, and H. Amirabadi, Finite Element Simulation of Machining Inconel 718 Alloy Including Microstructure Changes, Int. J. Mech. Sci., 2014, 88, p 110-121

10. E. Uhlmann, M. Graf von der Schulenburg, and R. Zettier, Finite Element Modeling and Cutting Simulation of Inconel 718, Ann. CIRP, 2007, 56(1), p 61-64

11. E. Uhlmann, R. Gerstenberger, and J. Kühnert, Cutting Simulation with the Mesh Free Finite Pointset Method, 14th CIRP Conference on Modeling of Machining Operations (CIRP CMMO), Proceedings of CIRP, 2013, 8, p 391-396

12. E. Uhlmann, M. Schulenburg, and R. Zettier, Finite Element Modeling and Cutting Simulation of Inconel 718, CIRP Ann. Manuf. Technol., 2007, 56(1), p 61-64

13. G. Warnecke and J.-D. Oh, A New Thermo-viscoplastic Material Model for Finite-Element Analysis of the Chip Formation Process, Ann. CIRP, 2002, 51(1), p 79-82

14. W. Grzesik, P. Nieslony, and M. Bartoszuk, Finite Element Modeling of Temperature Distribution in the Cutting Zone in Turning Processes with Differently Coated Tools, J. Mater. Proc. Technol., 2005, 164165, p 1204-1211

15. P. Niesłony, W. Grzesik, R. Chudy, and W. Habrat, Meshing Strategies in FEM Simulation of the Machining Process, Arch. Civ. Mech. Eng., $2015, \mathbf{1 5}(1)$, p $62-70$

16. P. Niesłony, W. Grzesik, P. Laskowski, and K. Żak, Numerical 3D FEM Simulation and Experimental Analysis of Tribological Aspects in Turning Inconel 718 Alloy, J. Mach. Eng., 2015, 15(1), p 46-57 